\title{
Article \\ The Impact of Orthodontic Treatment on Pre-Existing Gingival Recessions: A Retrospective Study
}

\author{
Guostè Antanavičienè ${ }^{1, *} \mathbb{0}$, Eglè Zasčiurinskiene ${ }^{1}$, Dalia Smailiené $^{1}$ and Nomeda Basevičienè ${ }^{2}$ \\ 1 Department of Orthodontics, Faculty of Odontology, Medical Academy, Lithuanian University of Health \\ Sciences, 44307 Kaunas, Lithuania; egle.zasciurinskiene@lsmuni.lt (E.Z.); dalia.smailiene@lsmuni.lt (D.S.) \\ 2 Department of Dental and Oral Pathology, Faculty of Odontology, Medical Academy, Lithuanian University \\ of Health Sciences, 44307 Kaunas, Lithuania; nomeda.baseviciene@lsmuni.lt \\ * Correspondence: guoste.baseviciute@gmail.com
}

Citation: Antanavičienè, G.; Zasčiurinskienè, E.; Smailienè, D.; Basevičienè, N. The Impact of Orthodontic Treatment on Pre-Existing Gingival Recessions: A Retrospective Study. Appl. Sci. 2021 11, 9036. https://doi.org/10.3390/ app11199036

Academic Editor: Rosa Valletta

Received: 19 August 2021

Accepted: 24 September 2021

Published: 28 September 2021

Publisher's Note: MDPI stays neutral with regard to jurisdictional claims in published maps and institutional affiliations.

Copyright: (c) 2021 by the authors. Licensee MDPI, Basel, Switzerland. This article is an open access article distributed under the terms and conditions of the Creative Commons Attribution (CC BY) license (https:// creativecommons.org/licenses/by/ $4.0 /)$.

\begin{abstract}
Background: This retrospective study aimed to examine the change of gingival recessions (GR) before and after orthodontic treatment (OT). (2) Methods: Patients who had at least one GR on the vestibular surface of maxillary/mandibular teeth mesial to first molars were included. GR was measured on good quality plaster models before and after OT. (3) Results: Significant improvement of mean GR at patient level was found between T0 and T1 $(0.45 \mathrm{~mm}, 95 \% \mathrm{CI}: 0.28,0.62)(p<0.001)$. In $51.4 \%$ of patients GRs became better, in $37.8 \%$ GRs did not change. and in $10.8 \%$ GRs became worse. At tooth level the mean GR improvement was $0.54 \mathrm{~mm}$ (CI: 0.42, 0.65; median $0.55 \mathrm{~mm}$ Q1; Q3: 0.12, $0.96)(p<0.001)$. GR improved in 67 teeth $(58.7 \%)$, did not change in $41(36.0 \%)$, and worsened in 6 (5.3\%). Full healing was observed in 15 teeth. A reduced GR improvement was found in cases with pre-treatment open bite (OR 3.89; CI: 1.35, 11.16; $p=0.008$ ) and dental Class III patients (OR 2.6; CI: $1.11,6.0 ; p=0.026$ ). (4) Conclusions: There was an improvement of GR after OT in more than half of the patients. Class III malocclusion and reduced pre-treatment overbite had a negative impact on GR improvement.
\end{abstract}

Keywords: gingival recession; orthodontics; tooth movement

\section{Introduction}

Gingival recession (GR) is defined as the apical shift of the gingival margin with respect to the cement-enamel junction. It is also associated with attachment loss and exposure of the root surface to the oral environment [1,2]. The consequences of GR include tooth sensitivity, root caries, hypermobility of the affected tooth and poor aesthetics [3,4].

Several GR classifications are available in the literature, with Miller's four categories of GR being the most widely used in orthodontics: Class I, where marginal tissue recession does not extend to the mucogingival junction (MGJ); Class II, where marginal tissue recession extends to or beyond the MGJ, but with no interdental periodontal attachment loss; Class III, where marginal tissue recession extends to or beyond the MGJ, with interdental bone or soft tissue loss or malpositioning of teeth, and, finally, Class IV, where marginal tissue recession extends to or beyond MGJ, with severe interdental bone or soft tissue loss and/or severe malpositioning of teeth [5]. In 2018 a new classification was introduced, in which GR is described by three categories based upon the interdental clinical attachment loss and predictability of root coverage outcomes [4,6]. Literature about the prevalence of different extent of GR is scarce, but GR of Miller class III and IV with interdental attachment loss is usually associated with the inflammatory periodontal disease and therefore is often not included in orthodontic research of periodontally healthy subjects [7].

The overall prevalence of GR affecting at least one tooth ranges from $11 \%$ to $90 \%$ in the adult population, being more frequent in adults aged 50 years and above [8-10]. The severity of GR has been observed to increase with age [8,11]. GR is more prevalent on vestibular surfaces and in mandibular teeth [9]. It is usually observed on one or 
several teeth; however, GR can be more widespread when the gingiva of multiple teeth is affected [12].

Although the pathogenesis of gingival recession remains unclear, there are several predisposing and precipitating factors, e.g., coronally attached frenulum and muscles, absence of attached gingiva, abnormal tooth position, overhanging restorations, proclination of teeth, thin mandibular alveolar bone, fenestration, dehiscence or mechanical trauma $[2,13]$. It has been observed that GRs greater than $3 \mathrm{~mm}$ are associated with facially aligned roots extending beyond the alveolar bony envelope [14]. As labial bone and crestal soft tissue thickness are highly associated, they may also influence the outcome of GR during different kinds of orthodontic movements $[15,16]$. To sum up, usually the main factors for GR development are presence of gingival retraction before orthodontic movement, poor oral hygiene, gingivitis and/or a thin gingival/bone biotype together with proclination of incisors [17].

Several clinical characteristics have been described for defining gingival biotype: crown width and length ratio, the width of keratinized tissue, papilla height and gingival thickness, which may be assessed by transgingival probing, ultrasonic measurement or probe visibility test [18]. However, method of visual inspection of the probe transparency through the gingiva is mostly recommended [19]. Studies have shown that subjects with a thin biotype are more prone to gingival marginal alterations, irrespective of the type of orthodontic movement. Thin periodontal biotype and proclination of teeth have been shown to correlate with loss of keratinized tissue [16]. It has also been found that the risk for the development of GR grows by $9.7 \%$ with each year after orthodontic treatment (OT) [20]. Canines, first premolars and first molars are most prone to GR after OT in the maxilla, while the highest risk of GR in the mandible was observed for the central incisors and first premolars [20].

The management of GR involves the elimination of etiological and predisposing factors and, if needed, surgical root coverage $[3,13]$. As untreated malocclusions have also been found to influence gingival problems (including GR), orthodontic therapy may favor tooth positions and be advantageous in the interdisciplinary treatment plan of GR management [21]. It has been described in the literature that moving a facially positioned tooth or its root in the lingual direction to a more centered position within the alveolar process, the apico-coronal dimension of gingival tissue will increase in width [2,22].

In the face of an increasing number of adult patients in orthodontic practice and the scarcity of the literature discussing recession changes, the investigation of the possible advantages of OT in the interdisciplinary management of pre-existing GR becomes essential. The literature up to date mainly focuses on the development of new GR after OT and mainly in patients before adulthood.

The present retrospective study aimed to examine changes (improvement, worsening or no change) in pre-existing GRs after orthodontic treatment.

Null hypothesis tested was that no change in pre-existing GRs may be observed after orthodontic tooth movement.

\section{Materials and Methods}

\subsection{Selection}

The present study was a retrospective clinical study. Ethical approval for the study was obtained (No. BEC-OF-67). Due to the retrospective design of the present study, we did not obtain written consent from the participants. Due to bioethics requirements in Lithuania, we obtained Ethical permission to analyze patients' records.

Intraoral photographs of 993 patients treated between January 2005 and November 2017 were analyzed. Flowchart of included patients is presented in Figure 1. 


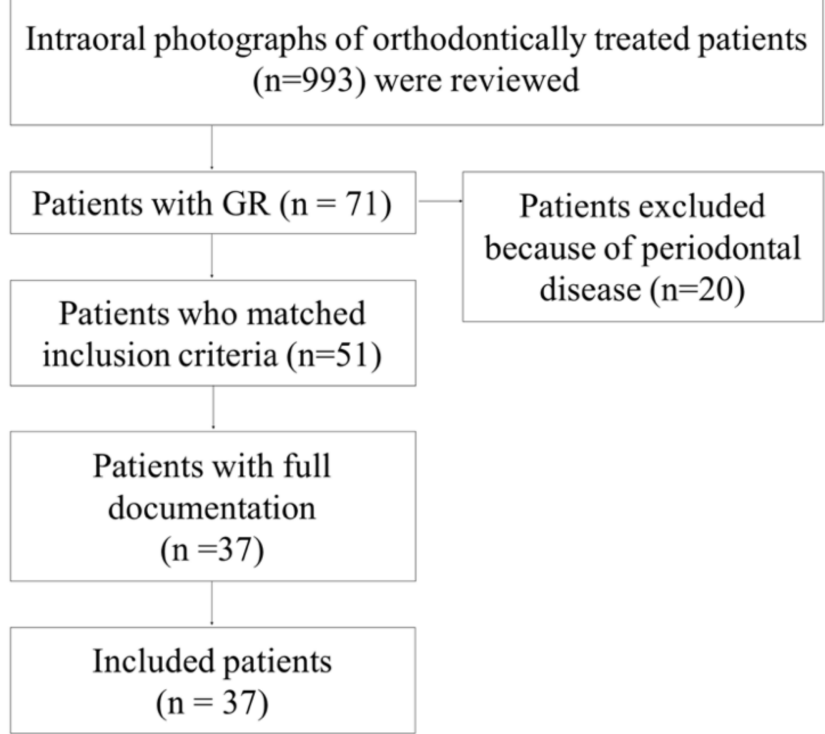

Figure 1. Flowchart of included patients with gingival recession.

Patients were treated by two orthodontists (authors EZ and DS) in the Department of Orthodontics, Faculty of Odontology at Lithuanian University of Health Sciences (LUHS) and the private practice in Kaunas, Lithuania. The presence of GR was identified on frontal, right and left buccal intraoral photographs (in occlusion) by one investigator, who was blinded (GA). The diagnosis was confirmed in patients' records and then measured on the plaster models (Figure 2).

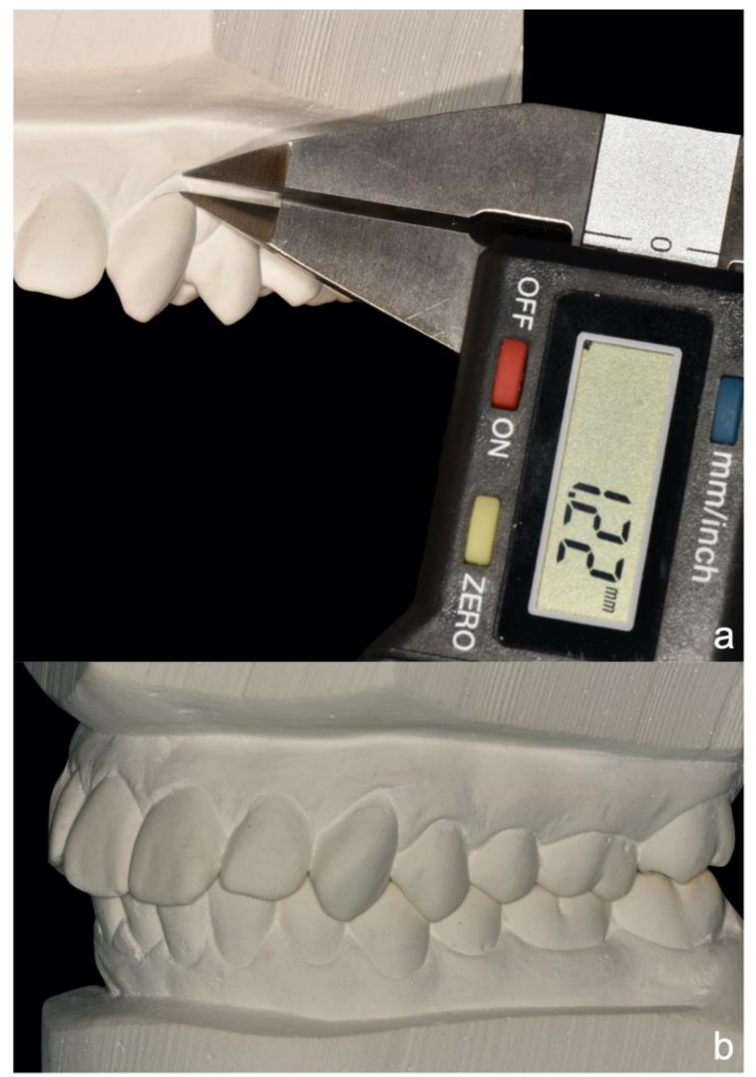

Figure 2. Gingival recession (GR) on plaster model. (a) - measurement of GR on tooth 23 with digital caliper; (b) - good quality of the plaster model. 
The presence of gingival recession was confirmed if the marginal border of the gingiva was apical to the cement-enamel junction. Patients with $\geq 1$ GR before OT were selected and included in the study. Inclusion criteria were: (1) $\geq 1$ GR before OT on labial surfaces of maxillary/mandibular teeth mesial to first molars; (2) dual arch OT with fixed orthodontic appliances; and (3) good quality plaster models available before and after OT. Exclusion criteria were: (1) periodontal disease; (2) OT without fixed orthodontic appliances; (3) systemic disease or medication that could influence the treatment outcome; (4) combined orthodontic-orthognathic treatment; and (5) surgical treatment of GR during OT. Only patients with the records of good oral hygiene without bleeding on probing $(\mathrm{BoP})$ were included. Professional oral hygiene was performed every 3-6 months during OT for all patients.

\subsection{Measurements}

\subsubsection{Patient Records}

- General data: age (years), gender (male, female), duration of orthodontic treatment (months).

- Tooth extraction (no extraction, extractions in the maxillary or mandibular dental arch, or extractions in both dental arches).

\section{Plaster Models}

All measurements were performed on plaster models before (T0) and after (T1) orthodontic treatment (the day of bracket debond) by the blinded calibrated observer (GA). No gingival enlargement at T1 was noted in patient records.

- The extent of gingival recession was measured in millimeters, using a digital caliper (Fino, Germany) before (T0) and after (T1) OT. Measurements were recorded to the nearest $0.01 \mathrm{~mm}$ (Figure 2). The change of GR (T0-T1) was categorized into three groups (worsened, did not change, improved (this group consists of healed GR, which became better but did not disappear, and fully healed-which disappeared after OT). Recession change of $\geq 0.5 \mathrm{~mm}$ was recorded as improvement or worsening [23,24].

- Overbite (OB), measured in millimeters before OT. OB values were categorized into three groups ( $<1 \mathrm{~mm} ; 1-3 \mathrm{~mm} ;>3 \mathrm{~mm})$ [25].

- Overjet $(\mathrm{OJ})$ was measured in millimeters before OT. Data were categorized into two groups ( $<4 \mathrm{~mm} ; \geq 4 \mathrm{~mm}$ ) [25].

- Sagittal relationship (between maxillary and mandibular canines). Class I was considered when upper canine displacement from the ideal position was less than $1 \mathrm{~mm}$.

- Crowding (yes/no) was determined according to the plaster models before OT.

- Position of teeth with GRs in the dental arch was assessed and classified to: (1) labial tooth position due to crowding, (2) labial/buccal root inclination, and (3) unfavorable occlusal contacts with antagonist teeth (cusp-to cusp or deep overbite).

\subsubsection{Intraoral Photographs}

Gingival biotype (normal/thick or thin) was determined blindly by two authors (NB and GA) according to intraoral photographs before OT based on tooth crown morphology and capillary transparency (Figure 3).

Kappa value between the investigators was 0.88 . The gingiva was identified as thin when triangular crowns and interproximal contacts close to the incisal edge were present, and the contours of tooth roots and the capillary network were easily visible [26,27]. The gingiva was recorded as thick/normal when square-shaped tooth crowns, large interproximal contact located more apically, and the contours of tooth roots and the capillary network were not visible $[18,26]$.

The primary outcome variable was the change in the extent of GR in relation to the cement-enamel junction (CEJ) from before to after OT (T0-T1). 


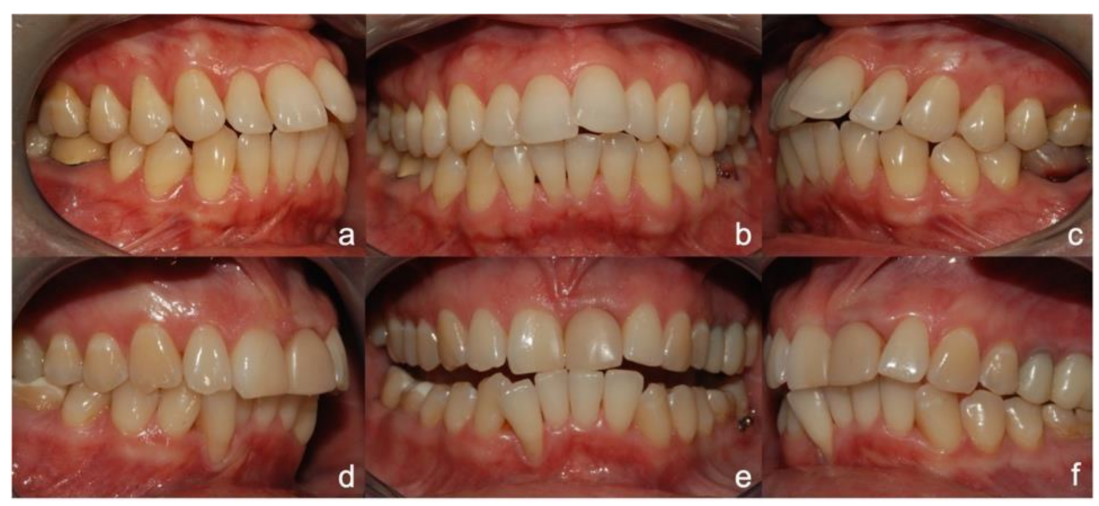

Figure 3. Biotype assessment from the digital photographs. (a-c) - thin biotype was recorded when triangular crowns and interproximal contacts close to the incisal edge were present; and the contours of tooth roots and the capillary network were easily visible; $(\mathbf{d}-\mathbf{f})$-thick/normal biotype was recorded when square-shaped tooth crowns and long interproximal contact located more apically were present; and the contours of tooth roots and the capillary network were not visible.

As the outcome of fixed appliance orthodontic treatment may be influenced by some specific treatment (e.g., duration of orthodontic treatment, extraction of teeth) or patientrelated factors (e.g., age, sex, gingival biotype, crowding), they were also analyzed [28,29].

\subsection{Data Preparation}

Firstly, analyses were performed on the patient as the unit of measure. Measurement analysis included all GRs at patient (cluster) level. GR change T0-T1 was evaluated by the mean millimeter change. Later, the analysis was performed at tooth (individual) level, taking into account possible clustering effects, to find out whether the number of teeth with GR changed within the patient during the treatment [30].

Also, analyses were performed at the tooth level. Three groups were created according to the change of GR: (1) improved-when the most apical point of GR approached cementenamel junction (the distance between the most apical point of GR and cement-enamel junction decreased (recession change was $\geq 0.5 \mathrm{~mm}$ and T0-T1 was positive); (2) did not change-when the distance between the most apical point of GR and cement-enamel junction changed by less than $0.5 \mathrm{~mm}$; (3) worsened - when the distance between the most apical point of GR and cement-enamel junction increased (change was $\geq 0.5 \mathrm{~mm}$ and T0-T1 was negative).

\subsection{Statistical Analysis}

Statistical analysis was performed using SPSS Statistics (Version 22.0. Armonk, NY, USA).

The interdependence of qualitative characteristics was evaluated using the chi-squared $\left(\chi^{2}\right)$ criterion. The Kolmogorov-Smirnov test was used to determine the normality of the parameter distribution. If variable distribution met the normality assumption, the Student's (t) criterion was applied to compare the quantitative sizes of two independent groups and one-way ANOVA for comparisons of three independent groups. When the variable did not meet the distribution normality condition, a significance level between two independent groups was verified by the Mann-Whitney U nonparametric method and Kruskal-Wallis test for three independent groups. For quantitative dependent variables, we used the paired test when distribution was normal, and the Wilcoxon nonparametric test when the test of normality of the investigated variables was denied.

The probability of the event given a certain risk factor was calculated using univariate and multivariate logistic regression analysis, including an odds ratio (OR) and its confidence interval $(95 \% \mathrm{CI})$.

The difference between groups was considered statistically significant when $p<0.05$. 
The intra-examiner error was estimated by performing gingival recession measurements twice with 1-week interval on plaster models before (T0) and after (T1) OT. Measurement error ranged between 0.16 and $0.37 \mathrm{~mm}$. For the assessment of the reproducibility of the measurements made by two investigators (GA and EZ), the inter-class correlation coefficient (ICC) was calculated. ICC revealed high agreement between 2 investigators (0.98; 95\% CI: 0.97; 0.99, $p=0.0001)$.

\section{Results}

\subsection{Baseline Data}

Fifty-one (5.1\%) patients of the 993 assessed treated by two orthodontists during 12 years had at least one vestibular GR before OT. Of those, 37 (72.5\%) patients, eight males (21.6\%) and 29 females (78.4\%) were included in the final analysis according to the inclusion criteria. The mean age of the included patients was 28.7 (95\% CI: 26.01, 31.40, range $13-51)$ years, and most of them were adults $(n=33)$. Orthodontic treatment lasted for a mean of $21.4(95 \%$ CI: $18.99,23.82)$ months. The characteristics of the included patients are presented in Table 1.

Table 1. Characteristics of included patients at baseline.

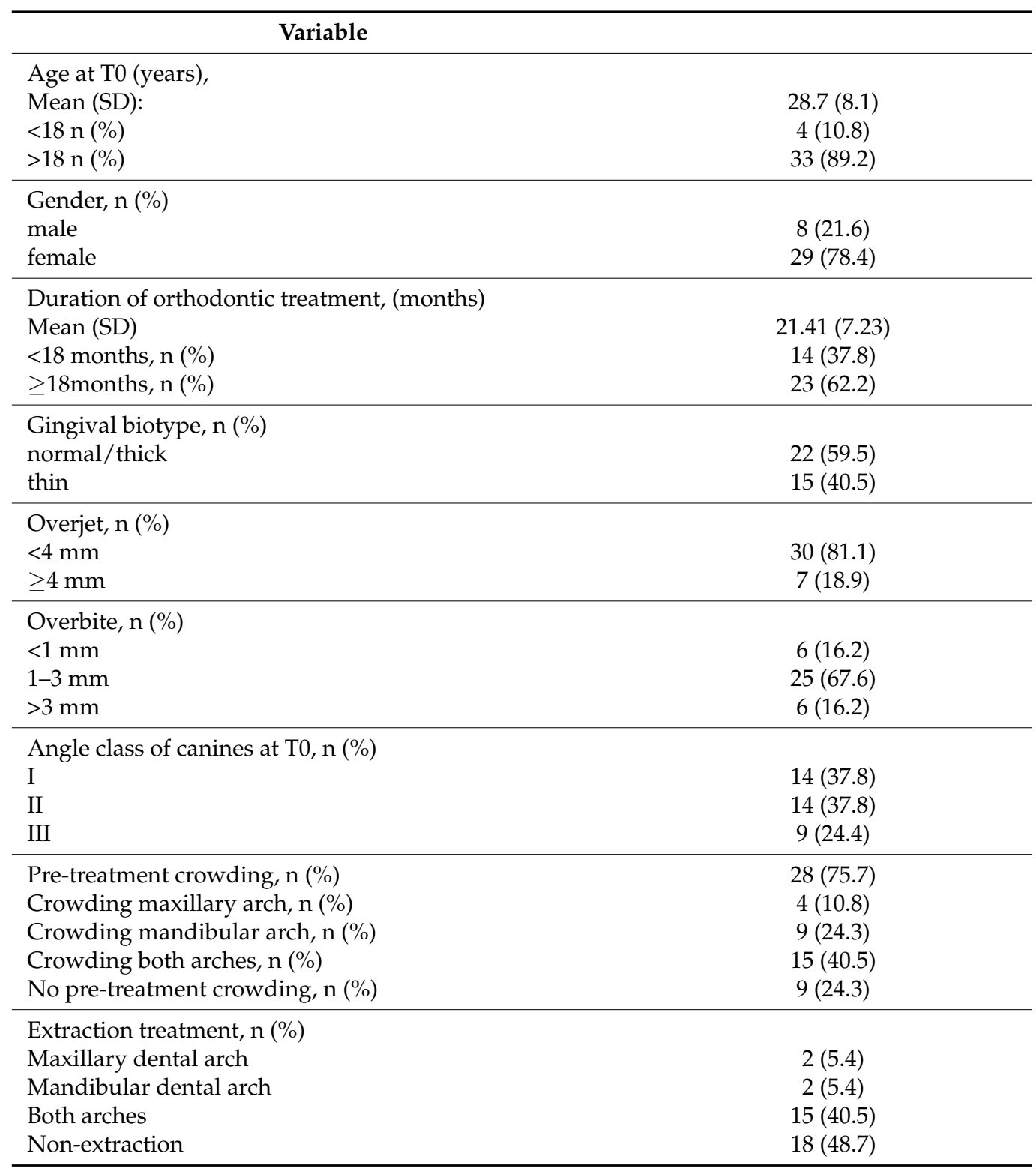




\subsection{Gingival Recession Change at Patient Level}

Mean GR before OT was $1.56 \mathrm{~mm}$ (CI: 1.34, 1.78); the number of teeth with GR within 37 patients before OT is shown in Figure 4.

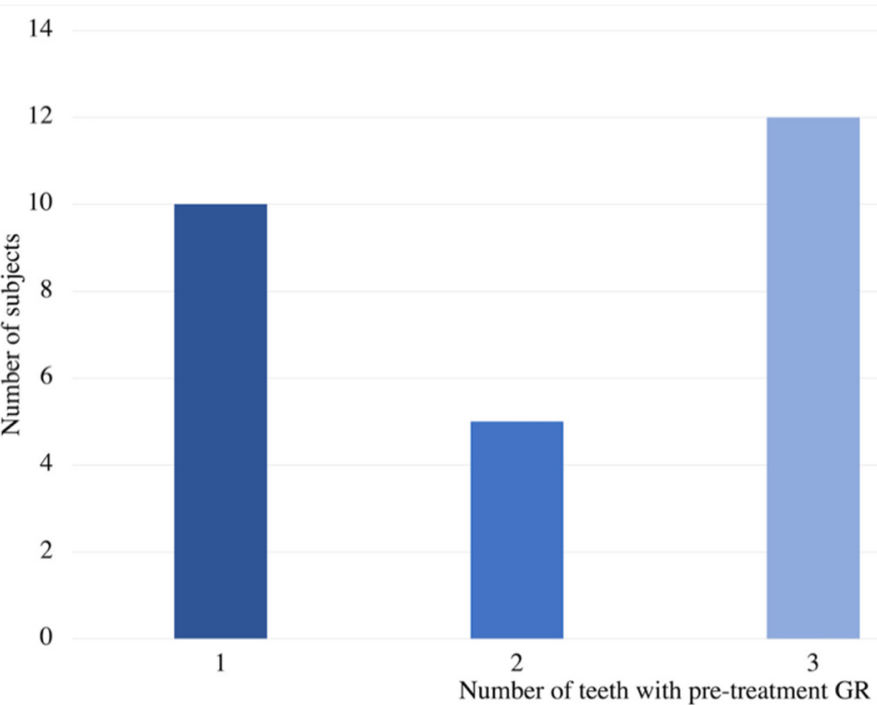

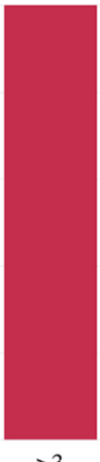

$>3$

Figure 4. Distribution of the number of teeth with pre-treatment gingival recessions in 37 patients.

Mean GR after OT reduced to $1.11 \mathrm{~mm}$ (CI: 0.89, 1.33). Significant improvement of mean GR was found between T0 and T1 $(0.45 \mathrm{~mm}, \mathrm{CI}: 0.28,0.62)(p=0.001)$. Ten patients had no improved GR, 9 patients had 1 improved GR, 9 patients had 2 improved GRs, 3 patients had 3 improved GRs, 2 patients had 4 improved GRs, 3 patients had 5 improved GRs and one patient had 8 improved GRs. In $51.4 \%$ of patients GRs became better, in $37.8 \%$ GRs did not change and in $10.8 \%$ GRs became worse. Change of gingival recessions after OT at a patient level is shown in Figure 5.

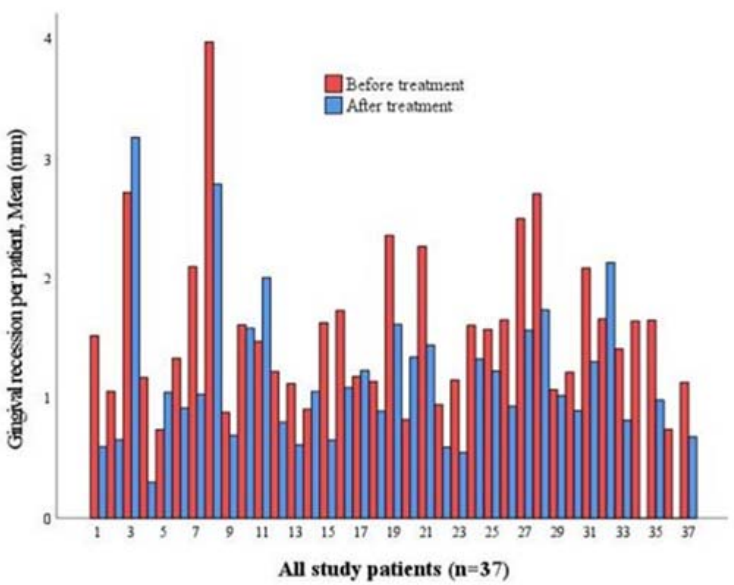

(a)

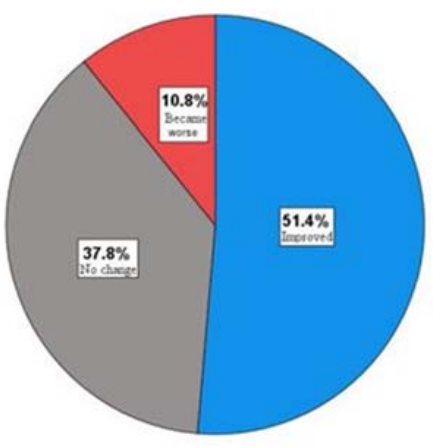

(b)

Figure 5. Comparison of gingival recession (GR) change before and after (OT) at patient level. (a)mean GR change before and after OT in every study patient; (b) - percentage of patients with GR change after OT (the cut-off value defining improvement or worsening was $0.5 \mathrm{~mm}$ ).

As significant GR change at patient level was found, the influence of specific patient and treatment factors were analyzed. 


\subsection{Patient-Related Factors}

- Sagittal relationship: Significant mean GR improvement was found in patients with dental Angle I ( $0.60 \mathrm{~mm}, \mathrm{CI}: 0.31,0.89 ; p=0.001)$ and Angle II $(0.47 \mathrm{~mm}, \mathrm{CI}: 0.20$; 0.74; $p=0.003)$, however, no significant GR changes were observed in Angle class III patients (mean $0.18 \mathrm{~mm}, \mathrm{CI}:-0.25 ; 0.61 ; p=0.44$ ). No difference between three groups in GR change was found $(p=0.21)$.

- Overbite: Significant median GR improvement after OT was found in patients with normal/deep $(\geq 1 \mathrm{~mm})$ pre-treatment overbite $(0.59 \mathrm{~mm}, \mathrm{Q} 1$; Q3: $0.28 ; 0.93)(p=0.001)$. No median GR improvement in subjects with a reduced overbite $(<1 \mathrm{~mm})$, rather a tendency to median recession worsening was observed $(0.002 \mathrm{~mm}, \mathrm{Q} 1$; Q3: -0.49 ; $0.36)(p=0.75)$. Significant difference in GR change between patients in three overbite groups was found $(p=0.03)$. Median GR improvement was significantly lower in patients with pre-treatment open bite $(<1 \mathrm{~mm})$ in comparison to normal $(1-3 \mathrm{~mm})$ $(p<0.05)$ or deep $(>3 \mathrm{~mm})(p<0.05)$ overbite.

- Biotype: Mean GR improvement from T0 to T1 was found in subjects with thin $(0.29 \mathrm{~mm}, \mathrm{CI}: 0.09,0.49 ; p=0.01 ; \mathrm{n}=15)$ and normal/thick biotype $(0.56 \mathrm{~mm}, \mathrm{CI}: 0.30$; $0.82 ; p=0.001 ; \mathrm{n}=22)$, with no significant differences between groups $(p=0.13)$.

- Overjet: No significant differences in patient-level GR changes were found between pre-treatment overjet $<4 \mathrm{~mm}$ and $\geq 4 \mathrm{~mm}$ subjects $(p=0.22)$.

- Crowding: No significant differences in patient-level GR changes were found between patients with $(\mathrm{n}=28)$ or without $(\mathrm{n}=9)$ pre-treatment crowding $(p=0.57)$.

- Sex: No significant differences in patient-level GR changes were found between males and females $(p=0.57)$.

- $\quad$ Age: No significant differences in patient-level GR changes were observed in adults ( $\geq 18$ years) and young $(<18$ years) subjects $(p=0.53)$.

\subsection{Treatment-Related Factors}

No differences in patient-level GR changes were found for the variables: OT duration $<18$ or $\geq 18$ months $(p=0.43)$ and extraction/no extraction groups $(p=0.89)$.

\subsection{Gingival Recession Change at Tooth Level}

718 teeth mesial to molars in 37 patients were evaluated before and after OT; of these, $114(15.9 \%)$ teeth had GR on the vestibular surfaces. Most of the GRs were Miller class I $(n=110)$ and only four teeth with Miller class II. The distribution of GRs before OT in different groups of teeth is presented in Figure 6.

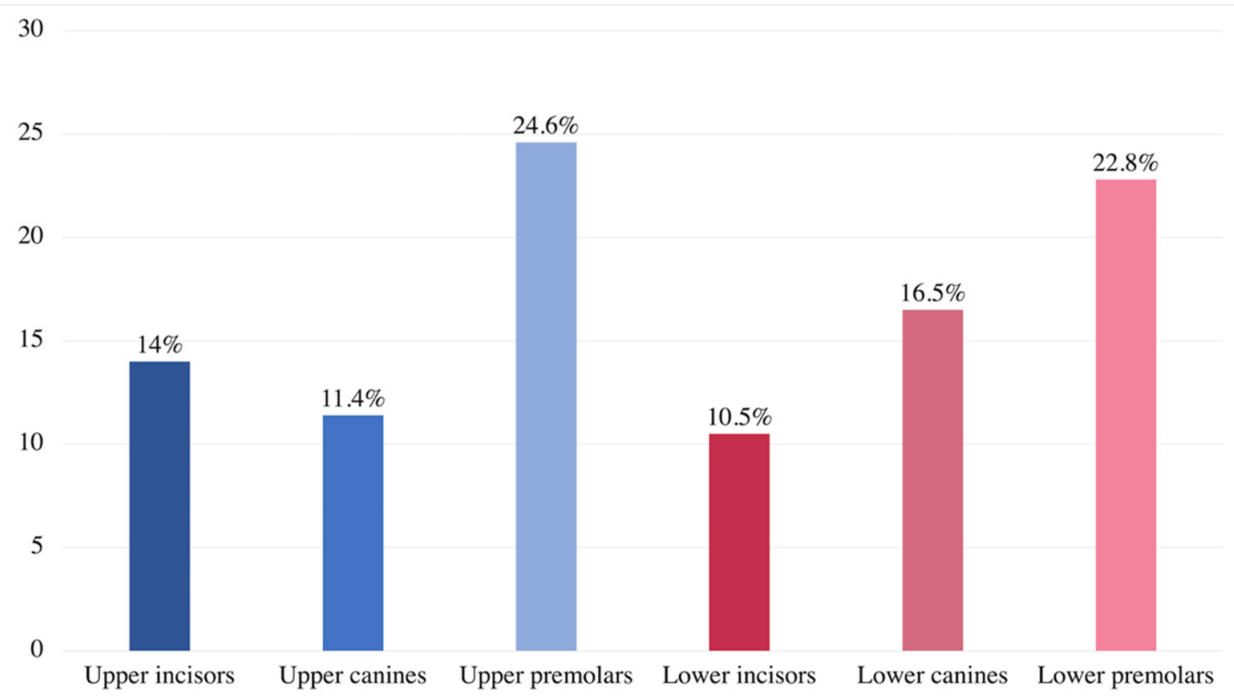

Figure 6. Distribution of pre-treatment gingival recessions in different groups of teeth. 
The median GR improvement was $0.55 \mathrm{~mm}(\mathrm{Q} 1, \mathrm{Q} 3: 0.12,0.96)(p=0.001)$, with $58.7 \%$ $(n=67)$ gingival recessions improved. From those 67 gingival recessions that improved (the cut-off value defining improvement or worsening was established at $0.5 \mathrm{~mm}$ ) 25 improved by $\geq 1.0 \mathrm{~mm}$. Complete resolution of GR was observed in 15 teeth out of 67 that improved $(22.4 \%)$ (Figure $7 \mathrm{a}-\mathrm{c}$ and $\mathrm{g}-\mathrm{j})$.

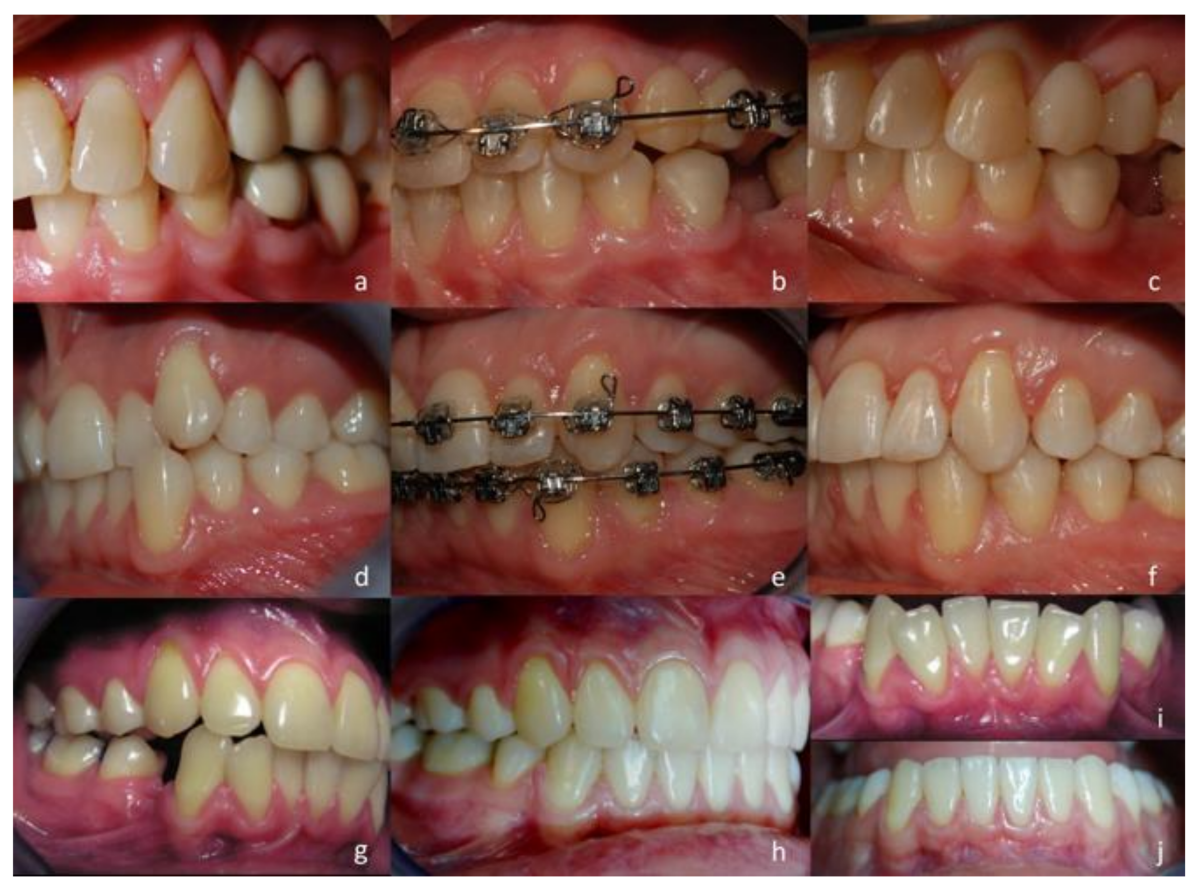

Figure 7. (a-c) - change of gingival recession when deep traumatic contact of tooth 23 was corrected by intrusion; (d-f) - no significant change of gingival recession of tooth 23 before, during and after orthodontic treatment; $(\mathbf{g}-\mathbf{j})$ —change of gingival recessions before and after orthodontic treatment of maxillary and mandibular anterior teeth due to more favorable centered position in the middle of alveolar bone.

GR did not change in $n=41(36 \%)$, and worsened in $n=6(5.3 \%)$ teeth. None of Miller class II gingival recessions healed. Numbers and different groups of teeth with GR change is presented in Table 2. The percentage of improved GR was highest on maxillary canines $(84.6 \%)$; however, the highest amount of GR improvement in millimetres was observed on maxillary and mandibular premolars $(p<0.001)$. Healing of GR was mostly ob-served on maxillary incisors (46.7\%). No recession was completely healed on mandibular incisors.

Table 2. Change of gingival recession in different groups of teeth.

\begin{tabular}{|c|c|c|c|c|}
\hline \multirow{2}{*}{ Tooth Group } & \multicolumn{4}{|c|}{ Change of Gingival Recession } \\
\hline & Improved n (\%) & No Change n (\%) & Became Worse n (\%) & Total n (100\%) \\
\hline Maxillary incisors & $10(62.5)$ & $5(31.3)$ & $1(6.3)$ & 16 \\
\hline Maxillary canines & $11(84.6)$ & $2(15.4)$ & $0(0.0)$ & 13 \\
\hline Maxillary premolars & $16(53.3)$ & $13(43.3)$ & $1(3.3)$ & 30 \\
\hline Mandibular incisors & $7(58.3)$ & $5(41.7)$ & $0(0.0)$ & 12 \\
\hline Mandibular canines & $10(52.6)$ & $8(42.1)$ & $1(5.3)$ & 19 \\
\hline Mandibular premolars & $13(54.2)$ & $8(33.3)$ & $3(12.5)$ & 24 \\
\hline Total & $67(58.8)$ & $41(36.0)$ & $6(5.3)$ & 114 \\
\hline
\end{tabular}


Median GR change in the different groups of teeth is presented in Figure 8.

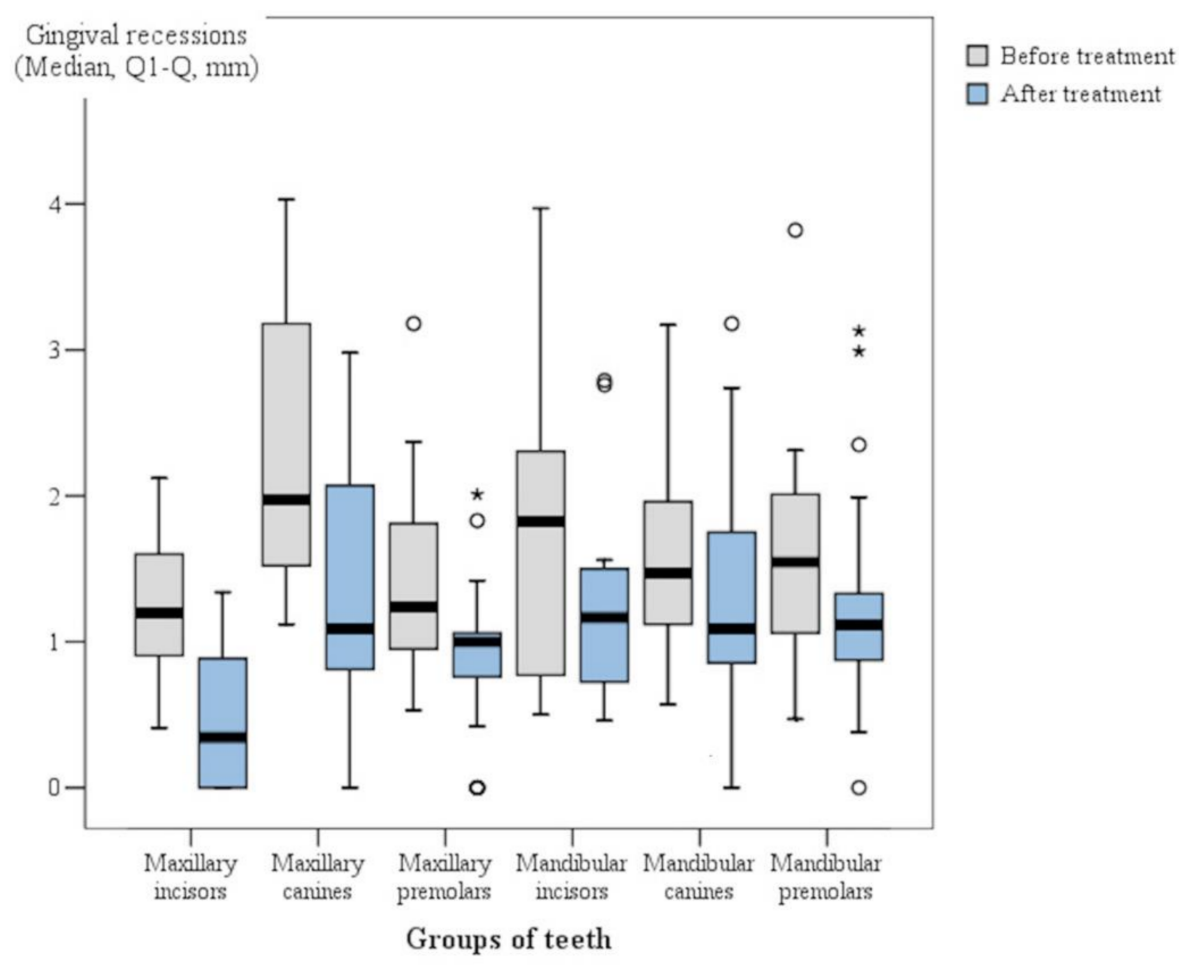

Figure 8. Median gingival recession change before and after orthodontic treatment in different groups of teeth. ${ }^{\circ},{ }^{*}$ - outliers.

The percentage of improved GR was highest on maxillary canines (84.6\%); however, the highest amount of GR improvement in millimeters was observed on maxillary and mandibular premolars $(p<0.001)$. Healing of GR was mostly observed on maxillary incisors (46.7\%). No recession was completely healed on mandibular incisors.

Median GR change after OT at tooth level in relation to different pre-treatment factors could be seen in Table 3 .

Table 3. Pre-treatment variables and gingival recessions before (T0) and after (T1) orthodontic treatment and recession change T0-T1 at tooth level.

\begin{tabular}{|c|c|c|c|c|c|}
\hline \multirow[b]{2}{*}{ Pre-Treatment Variable } & \multicolumn{5}{|c|}{ Gingival Recessions at Tooth Level (mm) Median (Q1; Q3) } \\
\hline & $\mathbf{N}$ & T0 & T1 & Change T0-T1 & $p$ \\
\hline- & 114 & $1.48(1.02 ; 2.03)$ & $0.65(0 ; 1.30)$ & $0.55(0.12 ; 0.96)$ & 0.001 \\
\hline Dental Angle I & 50 & $1.52(1.02 ; 2.02)$ & $0.95(0.54 ; 1.13)$ & $0.59 *(0.19 ; 1.11)$ & 0.001 \\
\hline Dental Angle II & 36 & $1.40(0.98 ; 2.06)$ & $1.04(0.60 ; 1.35)$ & $0.66(0.15 ; 0.90)$ & 0.001 \\
\hline Dental Angle III & 28 & $1.36(0.99 ; 2.21)$ & $1.09(0.92 ; 1.44)$ & $0.20 *(-0.08 ; 0.59)$ & 0.018 \\
\hline Normal overbite & 77 & $1.36(1.04 ; 1.97)$ & $0.95(0.54 ; 1.27)$ & $0.55^{+}(0.18 ; 0.92)$ & 0.001 \\
\hline Open bite or edge to edge & 19 & $1.16(0.95 ; 1.56)$ & $1.03(0.95 ; 1.57)$ & $0.11^{+,++}(-0.12 ; 0.52)$ & 0.40 \\
\hline Deep overbite & 18 & $2.08(1.07 ; 2.81)$ & $1.17(0.60 ; 1.95)$ & $0.86^{++}(0.49 ; 1.14)$ & 0.001 \\
\hline Overjet $<4 \mathrm{~mm}$ & 82 & $1.34(1.05 ; 1.91)$ & $1.02(0.60 ; 1.31)$ & $0.51(0.10 ; 0.87)$ & 0.001 \\
\hline Overjet $\geq 4 \mathrm{~mm}$ & 32 & $1.86(0.98 ; 2.33)$ & $1.08(071 ; 1.53)$ & $0.76(0.27 ; 1.11)$ & 0.001 \\
\hline Labial tooth position due to crowding & 38 & $1.56(1.00 ; 2.32)$ & $0.99(0.49 ; 1.95)$ & $0.57(0.09 ; 0.97)$ & 0.001 \\
\hline Labial/buccal root inclination & 48 & $1.36(1.00 ; 2.02)$ & $1.01(0.80 ; 1.23)$ & $0.54(0.14 ; 1.02)$ & 0.001 \\
\hline Traumatic contact & 28 & $1.31(1.05 ; 2.13)$ & $1.08(0.58 ; 1.55)$ & $0.52(0.08 ; 0.98)$ & 0.001 \\
\hline Thin biotype & 39 & $1.17(0.94 ; 1.64)$ & $0.95(0.61 ; 1.21)$ & $0.43^{* *}(0 ; 0.57)$ & 0.001 \\
\hline Normal/thick biotype & 75 & $1.63(1.14 ; 2.12)$ & $1.05(0.66 ; 1.42)$ & $0.74 * *(0.13 ; 1.08)$ & 0.001 \\
\hline
\end{tabular}

$p$ by Wilcoxon signed ranks test; ${ }^{*} p=0.004$ by 1-way ANOVA difference in GR change between three Angle groups and $p=0.003$ by Post Hoc Bonferroni test difference in GR change between Angle I and III patients; ${ }^{+,++} p=0.001$ by Kruskal-Wallis Test difference in GR change between three overbite groups and $p<0.01$ by Post Hoc Dunn's test.** $p=0.003$ by Student's t-test. 
A significant difference in GR change was found between three Angle classification ( $p=0.004)$ and overbite $(p=0.001)$ groups. The smallest GR change was found on teeth in Angle III and open bite patients. Teeth with thin gingival biotype were the less prone to GR improvement compared to thick/normal gingival biotype ( $p=0.003)$.

Univariate binary logistic regression analysis revealed a significant association between GR improvement $\geq 0.5 \mathrm{~mm}$ and overbite group $(<1 / \geq 1 \mathrm{~mm})$, also GR improvement $\geq 0.5 \mathrm{~mm}$ and Angle classification group (Angle III and Angle I/II). A reduced trend for GR improvement was observed in open bite (OR 3.89; 95\% CI: 1.35, 11.16; $p=0.008$ ) and Angle's class III participants (OR 2.6; CI: 1.11, 6.0; $p=0.026$ ). No statistically significant association between GR improvement $\geq 0.5 \mathrm{~mm}$ and biotype (thin and normal/thick) group was found $(p=0.12)$. Analysis showed collinearity between overbite and Angle classification groups $(r=0.25 p<0.008)$ and therefore multivariate regression analysis was not performed.

\section{Discussion}

The present retrospective study aimed to evaluate the change of GRs, which were present before OT. As the focus on mucogingival factors is increasing in the orthodontic literature due to the increasing number of adult subjects in orthodontic practice, it is essential to analyze whether the improvement in GR may be influenced by OT. The present study is one of the very few studies in the field to assess changes of pre-treatment GRs and related factors retrospectively. The available literature is more focused on the factors inducing GR after OT rather than changes [20,31,32]. According to a recent systematic review, there is a greater chance for GR to develop in orthodontically treated patients, especially in retention period [33]. However, further, especially prospective studies are still needed.

In the present study, only $5.1 \%$ of patients with pre-existing GR were identified from the 12-year clinical material of 2 orthodontists showing rather low prevalence. The included patients were different in the type of dental malocclusion, the number of gingival recessions and other variables, partly explaining the current scarcity of the prospective studies. Most of the included cases were adult patients ( $\geq 18$ years old $)(n=33)$, showing that GRs are more prevalent in adult patients and confirming findings in the literature [11]. GRs in young subjects $(<18$ years old) have been described to be associated with atypical tooth position; however, there were very few subjects $<18$ years in the present study $(n=4)$ [34].

The measurements of 114 GRs in 37 patients were performed calculating the distance between the most apical marginal gingival contour and cement-enamel junction using a digital caliper, which is more accurate than using a periodontal probe [35]. In the recent article, authors found that measurements on digital models were the most accurate; however, their caliper was not digital, and this could influence the results [35]. Other authors compared pre-treatment and post-treatment clinical crown heights; however, this kind of measurement in adults could be affected by incisal wear and/or restorations during OT [20,36]. At tooth level, due to the small numbers of recession measurements, we recorded improvement only when it was clinically significant (change from T0 to T1 was $\geq 0.5 \mathrm{~mm}$ ), so actual percentage with GR improvement could be higher. Changes of clinical periodontal variables are usually small and are in line with the findings of the present study [37].

The results of the present study revealed a positive impact of OT on the GR change. Change of GRs was similar at patient $(0.45 \mathrm{~mm})$ and tooth $(0.55 \mathrm{~mm})$ levels confirming that orthodontic movements to a more centered tooth positions in the alveolar bone are of major importance [21]. Possible confounding factors such as surgical treatment of GR during OT, periodontal disease and systemic disease or medication that could influence treatment outcome were excluded from the study. There were also no influences of sex, age or treatment duration on GR change.

Furthermore, we found that GRs improved in more than half of the patients. A high percentage of improved GRs could be influenced by gingival enlargement during OT. However, gingival enlargement is mostly prevalent in teenagers with compromised oral 
hygiene; this study comprised mostly of adults with good oral hygiene, so the influence of this factor is not discussed. Tooth group was found to be important to GR changes. The present study showed the most significant amount of GR improvement in maxillary premolars and mandibular premolars. The study by Melsen et al. (2005) showed equal amounts of improved and worsened GRs (42.3\%) [31]. It is worth mentioning that these authors examined recessions only on mandibular incisors, which improved in more than half in our study; however, none of them fully healed. Mandibular incisors might be described most frequently because of the highest prevalence of new GRs after OT on their labial surfaces. The incomplete healing of GRs in mandibular incisors which was found in the present study may be explained by the fact that the labial alveolar bone is anatomically very thin already before OT, and may predispose the development of dehiscences after orthodontic movement of these teeth [38]. The percentage of improved GRs in the present study was largest on maxillary canines (84.6\%), which is in contrast to the results of Boke et al. (2014), where GRs worsened after orthodontic treatment [26]. That could be influenced by the negative torque, usual in Roth prescription brackets, sometimes leading to a significant labial movement of the canine root. In the present study, all patients were treated with maxillary canine torque of $0^{\circ}$ or $+7^{\circ}$. Careful bracket torque selection for teeth with GR's, bearing in mind the position of the root in the alveolus, could have influenced our results. However, this is only a speculation, as the present study had a retrospective design.

As the study patients had different malocclusions, we found it essential to analyze patient-related factors, which could have influenced GR change. Pre-treatment overbite had an impact on GR change: patients with reduced overbite had a tendency for GR worsening in comparison to normal/deep overbite cases, where improvement of GR was found. The results are in line with the results by Zimmer et al. (2007), where an average improvement of $2 \mathrm{~mm}$ in GRs was observed in maxillary incisors [36]. The sample consisted mainly patients with traumatic deep bite. Therefore, a significant improvement in GR was related to the elimination of the causative factor-mechanical load. Based on the results of the present study and earlier studies, it may be expected that the treatment of deep overbite may favor the improvement of GR. Enhos et al. (2012) also found that patients with hypodivergent vertical growth pattern (deep bite) have a lower prevalence of dehiscence than those with a normo-divergent or hyper-divergent (open bite) growth pattern [39].

GR improvement in the present study was similar in both pre-treatment increased and decreased overjet at the patient level and tooth level. However, in the study by Boke et al. (2014) authors found that decreasing incisor proclination had positive effect on the improvement of GR. Later studies by Kamak et al. (2015) and Morris et al. (2017) did not find such an association, suggesting that correction of increased overjet does not influence GR change [40,41].

Gingival biotype at patient level did not result in significantly different GR change; however, at tooth level, a smaller improvement was found in teeth with thin biotype. Some authors suggest that GRs are less likely to improve after OT in cases with thin biotype [42]. However, in the study by Boke et al. (2014), no association between GR change and gingival biotype was reported suggesting that gingival thickness is not the most critical factor [26].

The sagittal dental relationship has also been found to influence GR change. The literature mostly describes Angle class III cases as risk factors to GR worsening after OT, mainly due to retroclination of lower incisors to camouflage malocclusion [32]. Sperry et al. observed that Class III patients with excessive dental compensations had more than three times as many teeth with labial GRs after OT in comparison to patients with Class I or Class II [43]. The results of the present study support these findings: no significant GR improvement was found in Angle III patients. Patients with a Class III relationship had 2.6-times less chance for GR improvement than those with Class I or II. This observation can be explained by the anatomically thin buccal cortical plate, and the presence of dehiscences and fenestrations in the mandibular incisor region found in all types of untreated sagittal malocclusions [38]. Therefore, lingual movement of the lower incisor crowns, in order to 
compensate Class III malocclusion, may result in labial movement of incisor roots, thereby causing or worsening GR [32]. Maxillary anterior teeth usually undergo proclination due to dentoalveolar compensation in Class III patients, which has also been found to induce the development or worsening of GR [42]. Therefore, the net effect is that Class III patients have a risk of GR worsening during OT.

Even if the percentage of worsened GRs in the present study was small (both at patient and tooth levels), it is hard to make conclusions. It is important to know that most of the worsened GRs were in patients with Angle class III dental relationship or reduced pretreatment overbite.

No difference in GR change after OT was found between teeth with pretreatment labial tooth position due to crowding, labial/buccal root inclination or unfavorable occlusal contacts with antagonist teeth [12]. Interestingly, GR improvements were somewhat similar despite etiologic factor suggesting that recession improvement may be reached by correction of malocclusion, knowing that the main key is trying to retain the roots within the alveolar bony envelope [28,44].

The results of the present study reveal that orthodontic tooth movements favoring better position of tooth roots in the alveolar bony envelope by lingually moving labially positioned teeth, or lingually inclining tooth roots (e.g., by selecting appropriate bracket torque), which may increase width of apico-coronal dimension of gingival tissue has to be the primary aim in treating subjects with GRs [2,21,22]. Moreover, the use of CBCT, especially in cases with thin periodontal phenotype, has been recommended by American Academy of Periodontology for planning orthodontic tooth movements, especially when labial/buccal movements are needed. As comprehensive orthodontic treatment induces changes in the buccal aspect of alveolar bone, CBCT provides three-dimensional information about alveolar bone thickness and defects and serves for both: planning of orthodontic movements and timing of periodontal augmentation procedures, where needed [45].

It is important to know that orthodontic treatment, especially debonding of fixed appliances, can be linked with a higher sensitivity usually in the anterior teeth, as shown by recent research [46].

The clinical relevance of the present study is that orthodontic movements, together with some related factors, may induce GR change. The results of the present article show the merit of OT in adult patients with pre-treatment GRs. Therefore, confirming the necessity of interdisciplinary collaboration. The tendency of GRs to be improved may be expected in the normal/deep overbite cases, however more in maxillary teeth. However, GRs in open bite and Class III cases, also on mandibular anterior teeth, if present before OT, may need soft tissue augmentation, especially when planning unfavorable camouflage movements in relation to the alveolar bone envelope. This decision is more critical in thin gingival biotype cases [22].

Since $58.8 \%(n=67)$ of GRs improved, and $22.4 \%(n=15)$ of them were completely healed, the null hypothesis was rejected.

Limitations of the present study included retrospective design and the measurements performed on plaster models, which were fabricated directly after bracket debonding. The use of plaster models can be problematic as they can be damaged and result in inaccurate measurements, which could influence the results. Also, we can't guarantee that during 12 years exactly the same materials were used for impressions. However, only good quality plaster models were included in the present study and GR measurements were performed with a digital caliper. In a prospective study, we would recommend to wait 3-6 months after OT and perform direct measurements of GR or to perform measurements using digital models [35].

Another limitation is that gingival biotype evaluation was performed on intraoral photographs. Gingival biotype assessment would ideally require clinical examination of the patient, which was not possible because of retrospective study [19,35].

The sample size was small, however many years would be needed to collect clinically uniform groups for comparison. 
The need for prospective and follow up studies is warranted to confirm the results of the present study.

\section{Conclusions}

Based on the findings of the present retrospective study, it may be concluded that orthodontic treatment induces changes in gingival recessions. Improvement of gingival recession was observed in more than half of the teeth. Class III malocclusion and reduced pre-treatment overbite had a negative impact on GR improvement.

Author Contributions: All authors were involved in manuscript preparation. Author E.Z. was responsible for the project. Authors E.Z. and D.S. treated patients. Measurements were made by two investigators (G.A. and E.Z.). Author N.B. consulted and assessed periodontology aspects of the manuscript. All authors have read and agreed to the published version of the manuscript.

Funding: This research received no external funding.

Institutional Review Board Statement: Ethical approval for the study was received by Bioethics Center at Lithuanian University of Health Sciences (No. BEC-OF-67).

Informed Consent Statement: Due to the retrospective design of the present study, we did not obtain written consent from the participants. Due to bioethics requirements in Lithuania, we obtained Ethical permission to analyze patients' records.

Data Availability Statement: The datasets used and/or analyzed during the current study are available from the corresponding author on reasonable request.

Acknowledgments: Authors acknowledge help and support of colleagues in private dental centers "Odontologijos praktikos centras", "Lazerinès odontologijos centras" and "\& SMILE" while collecting data for this study. Authors also acknowledge university statistician Irena Nedzelskiene for the help with statistical analysis.

Conflicts of Interest: The authors declare no conflict of interest.

$\begin{array}{ll}\text { Abbreviations } \\ \text { GR } & \text { gingival recession } \\ \text { MGJ } & \text { mucogingival junction } \\ \text { OT } & \text { orthodontic treatment } \\ \text { OB } & \text { overbite } \\ \text { OJ } & \text { overjet }\end{array}$

\section{References}

1. Manson, J.D.; Eley, B.M. Mucogingival problems and their treatment. In Outline of Periodontics; Manson, J.D., Eley, B.M., Eds.; Elsevier Health Sciences: London, UK, 2000.

2. Cortellini, P.; Bissada, N.F. Mucogingival conditions in the natural dentition: Narrative review, case definitions, and diagnostic considerations. J. Periodontol. 2018, 89 (Suppl. 1), S204-S213. [CrossRef]

3. Tugnait, A.; Clerehugh, V. Gingival recession-its significance and management. J. Dent. 2001, 29, 381-394. [CrossRef]

4. Jepsen, S.; Caton, J.G.; Albandar, J.M.; Bissada, N.F.; Bouchard, P.; Cortellini, P.; Demirel, K.; de Sanctis, M.; Ercoli, C.; Fan, J.; et al. Periodontal manifestations of systemic diseases and developmental and acquired conditions: Consensus report of workgroup 3 of the 2017 World Workshop on the Classification of Periodontal and Peri-Implant Diseases and Conditions. J. Clin. Periodontol. 2018, 45 (Suppl. 20), S219-S229. [CrossRef] [PubMed]

5. Miller, P.D. A classification of marginal tissue recession. Int. J. Periodontics Restor. Dent. 1985, 5, 8-13. [PubMed]

6. Cairo, F.; Nieri, M.; Cincinelli, S.; Mervelt, J.; Pagliaro, U. The interproximal clinical attachment level to classify gingival recessions and predict root coverage outcomes: An explorative and reliability study. J. Clin. Periodontol. 2011, 38, 661-666. [CrossRef] [PubMed]

7. Pini-Prato, G. The Miller classification of gingival recession: Limits and drawbacks. J. Clin. Periodontol. 2011, 38, $243-245$. [CrossRef] [PubMed]

8. Loe, H.; Anerud, A.; Boysen, H. The natural history of periodontal disease in man: Prevalence, severity, and extent of gingival recession. J. Periodontol. 1992, 63, 489-495. [CrossRef]

9. Marini, M.G.; Greghi, S.L.; Passanezi, E.; Sant'ana, A.C. Gingival recession: Prevalence, extension and severity in adults. J. Appl. Oral Sci. 2004, 12, 250-255. [CrossRef] [PubMed] 
10. Sarfati, A.; Bourgeois, D.; Katsahian, S.; Mora, F.; Bouchard, P. Risk assessment for buccal gingival recession defects in an adult population. J. Periodontol. 2010, 81, 1419-1425. [CrossRef] [PubMed]

11. Mythri, S.; Arunkumar, S.M.; Hegde, S.; Rajesh, S.K.; Munaz, M.; Ashwin, D. Etiology and occurrence of gingival recession-An epidemiological study. J. Indian Soc. Periodontol. 2015, 19, 671-675. [CrossRef]

12. Jati, A.S.; Furquim, L.Z.; Consolaro, A. Gingival recession: Its causes and types, and the importance of orthodontic treatment. Dent. Press J. Orthod. 2016, 21, 18-29. [CrossRef]

13. Kassab, M.M.; Cohen, R.E. The etiology and prevalence of gingival recession. J. Am. Dent. Assoc. 2003, 134, 220-225. [CrossRef] [PubMed]

14. Richman, C. Is gingival recession a consequence of an orthodontic tooth size and/or tooth position discrepancy? "A paradigm shift". Compend. Contin. Educ. Dent. 2011, 32, e73-e79.

15. Le, B.T.; Borzabadi-Farahani, A. Labial bone thickness in area of anterior maxillary implants associated with crestal labial soft tissue thickness. Implant. Dent. 2012, 21, 406-410. [CrossRef] [PubMed]

16. Rasperini, G.; Acunzo, R.; Cannalire, P.; Farronato, G. Influence of Periodontal Biotype on Root Surface Exposure During Orthodontic Treatment: A Preliminary Study. Int. J. Periodontics Restor. Dent. 2015, 35, 665-675. [CrossRef] [PubMed]

17. Flores-Mir, C. Does orthodontic treatment lead to gingival recession? Evid. Based Dent. 2011, 12, 20. [CrossRef] [PubMed]

18. Zweers, J.; Thomas, R.Z.; Slot, D.E.; Weisgold, A.S.; Van der Weijden, F.G. Characteristics of periodontal biotype, its dimensions, associations and prevalence: A systematic review. J. Clin. Periodontol. 2014, 41, 958-971. [CrossRef]

19. Cosgarea, R.; Kloukos, D.; Katsaros, C.; Sculean, A. Etiology and Treatment of Gingival Recessions in Orthodontically Treated Patients. In The Ortho-Perio Patient. Clinical Evidence \& Therapeutic Guidelines, 1st ed.; Eliades, T., Katsaros, C., Eds.; Quintessence Publishing Co. Inc.: Batavia, IL, USA, 2019.

20. Renkema, A.M.; Fudalej, P.S.; Renkema, A.; Kiekens, R.; Katsaros, C. Development of labial gingival recessions in orthodontically treated patients. Am. J. Orthod. Dentofac. Orthop. 2013, 143, 206-212. [CrossRef]

21. Renkema, A.M.; Fudalej, P.S.; Renkema, A.A.; Abbas, F.; Bronkhorst, E.; Katsaros, C. Gingival labial recessions in orthodontically treated and untreated individuals: A case-control study. J. Clin. Periodontol. 2013, 40, 631-637. [CrossRef]

22. Gorbunkova, A.; Pagni, G.; Brizhak, A.; Farronato, G.; Rasperini, G. Impact of Orthodontic Treatment on Periodontal Tissues: A Narrative Review of Multidisciplinary Literature. Int. J. Dent. 2016, 2016, 4723589. [CrossRef]

23. Cesar Neto, J.B.; Cavalcanti, M.C.; Sekiguchi, R.T.; Pannuti, C.M.; Romito, G.A.; Tatakis, D.N. Root Coverage for Single Deep Gingival Recessions: Outcomes Based on a Decision-Making Algorithm. Int. J. Dent. 2019, 2019, 1830765. [CrossRef] [PubMed]

24. Goodson, J.M.; Haffajee, A.D.; Socransky, S.S.; Kent, R.; Teles, R.; Hasturk, H.; Bogren, A.; Van Dyke, T.; Wennstrom, J.; Lindhe, J. Control of periodontal infections: A randomized controlled trial I. The primary outcome attachment gain and pocket depth reduction at treated sites. J. Clin. Periodontol. 2012, 39, 526-536. [CrossRef] [PubMed]

25. Proffit, W.R. Malocclusion and Dentofacial Deformity in Contemporary Society. In Contemporary Orthodontics-E-Book; Proffit, W.R., Fields, H.W., Larson, B., Sarver, D.M., Eds.; Elsevier Health Sciences: Philadelphia, PA, USA, 2018.

26. Boke, F.; Gazioglu, C.; Akkaya, S.; Akkaya, M. Relationship between orthodontic treatment and gingival health: A retrospective study. Eur. J. Dent. 2014, 8, 373-380. [CrossRef] [PubMed]

27. Esfahrood, Z.R.; Kadkhodazadeh, M.; Talebi Ardakani, M.R. Gingival biotype: A review. Gen. Dent. 2013, 61, 14-17. [PubMed]

28. Johal, A.; Katsaros, C.; Kiliaridis, S.; Leitao, P.; Rosa, M.; Sculean, A.; Weiland, F.; Zachrisson, B. State of the science on controversial topics: Orthodontic therapy and gingival recession (a report of the Angle Society of Europe 2013 meeting). Prog. Orthod. 2013, 14, 16. [CrossRef] [PubMed]

29. Wishney, M. Potential risks of orthodontic therapy: A critical review and conceptual framework. Aust. Dent. J. 2017, 62 (Suppl. 1), 86-96. [CrossRef] [PubMed]

30. Koletsi, D.; Pandis, N.; Polychronopoulou, A.; Eliades, T. Does published orthodontic research account for clustering effects during statistical data analysis? Eur. J. Orthod. 2012, 34, 287-292. [CrossRef] [PubMed]

31. Melsen, B.; Allais, D. Factors of importance for the development of dehiscences during labial movement of mandibular incisors: A retrospective study of adult orthodontic patients. Am. J. Orthod. Dentofac. Orthop. 2005, 127, 552-561. [CrossRef]

32. Vasconcelos, G.; Kjellsen, K.; Preus, H.; Vandevska-Radunovic, V.; Hansen, B.F. Prevalence and severity of vestibular recession in mandibular incisors after orthodontic treatment. Angle Orthod. 2012, 82, 42-47. [CrossRef]

33. Bin Bahar, B.S.K.; Alkhalidy, S.R.; Kaklamanos, E.G.; Athanasiou, A.E. Do orthodontic patients develop more gingival recession in anterior teeth compared to untreated individuals? A systematic review of controlled studies. Int. Orthod. 2020, 18, 1-9. [CrossRef] [PubMed]

34. Chrysanthakopoulos, N.A. Gingival recession: Prevalence and risk indicators among young greek adults. J. Clin. Exp. Dent. 2014, 6, e243-e249. [CrossRef]

35. Fageeh, H.N.; Meshni, A.A.; Jamal, H.A.; Preethanath, R.S.; Halboub, E. The accuracy and reliability of digital measurements of gingival recession versus conventional methods. BMC Oral Health 2019, 19, 154.

36. Zimmer, B.; Seifi-Shirvandeh, N. Changes in gingival recession related to orthodontic treatment of traumatic deep bites in adults. J. Orofac. Orthop. 2007, 68, 232-244. [CrossRef] [PubMed]

37. Papageorgiou, S.N.; Papadelli, A.A.; Eliades, T. Effect of orthodontic treatment on periodontal clinical attachment: A systematic review and meta-analysis. Eur. J. Orthod. 2018, 40, 176-194. [CrossRef] [PubMed] 
38. Yagci, A.; Veli, I.; Uysal, T.; Ucar, F.I.; Ozer, T.; Enhos, S. Dehiscence and fenestration in skeletal Class I, II, and III malocclusions assessed with cone-beam computed tomography. Angle Orthod. 2012, 82, 67-74. [CrossRef] [PubMed]

39. Enhos, S.; Uysal, T.; Yagci, A.; Veli, I.; Ucar, F.I.; Ozer, T. Dehiscence and fenestration in patients with different vertical growth patterns assessed with cone-beam computed tomography. Angle Orthod. 2012, 82, 868-874. [CrossRef] [PubMed]

40. Kamak, G.; Kamak, H.; Keklik, H.; Gurel, H.G. The effect of changes in lower incisor inclination on gingival recession. Sci. World J. 2015, 2015, 193206. [CrossRef]

41. Morris, J.W.; Campbell, P.M.; Tadlock, L.P.; Boley, J.; Buschang, P.H. Prevalence of gingival recession after orthodontic tooth movements. Am. J. Orthod. Dentofac. Orthop. 2017, 151, 851-859. [CrossRef]

42. Joss-Vassalli, I.; Grebenstein, C.; Topouzelis, N.; Sculean, A.; Katsaros, C. Orthodontic therapy and gingival recession: A systematic review. Orthod. Craniofac. Res. 2010, 13, 127-141. [CrossRef]

43. Sperry, T.P.; Speidel, T.M.; Isaacson, R.J.; Worms, F.W. The role of dental compensations in the orthodontic treatment of mandibular prognathism. Angle Orthod. 1977, 47, 293-299.

44. Wennstrom, J.L. Mucogingival considerations in orthodontic treatment. Semin. Orthod. 1996, 2, 46-54. [CrossRef]

45. Mandelaris, G.A.; Neiva, R.; Chambrone, L. Cone-beam computed tomography and interdisciplinary dentofacial therapy: An American academy of periodontology best evidence review focusing on risk assessment of the dentoalveolar bone changes influenced by tooth movement. J. Periodontol. 2017, 88, 960-977. [CrossRef] [PubMed]

46. Scribante, A.; Gallo, S.; Celmare, R.L.; D'Antò, V.; Grippaudo, C.; Gandini, P.; Sfondrini, M.F. Orthodontic debonding and tooth sensitivity of anterior and posterior teeth. Angle Orthod. 2020, 90, 766-773. [CrossRef] [PubMed] 